\title{
Prosthetic joint infection due to Salmonella species: a case series
}

\author{
Arjun Gupta ${ }^{1,2}$, Elie F Berbari ${ }^{1}$, Douglas R Osmon ${ }^{1}$ and Abinash Virk*
}

\begin{abstract}
Background: Prosthetic joint infection (PJI) due to Salmonella is rare. Numerous outbreaks of Salmonella have been reported throughout the United States in the last decade. We reviewed and analyzed cases of Salmonella PJI seen at our institution.

Methods: The medical records of all patients diagnosed with a Salmonella PJI between 1969-2013 were reviewed. Patients were followed till death, treatment failure or loss to follow-up.

Results: Six patients of Salmonella PJI were identified during the 44 year study period. Five were male; median age was 63.5 years (range 52-76). Five patients were immunodeficient. Five had a total hip arthroplasty infection, while one had a total knee arthroplasty infection. Median prosthesis age at the time of diagnosis of first episode of Salmonella PJI was 5 years (range 4 months-9 years). Four presented with fever and constitutional signs within two weeks of symptom onset. Two patients each had gastrointestinal symptoms and Salmonella bacteremia. Salmonella enterica serovar Enteritidis was the most common organism isolated (4 patients). None were Salmonella enterica serovar Typhi. Initial management included aspiration and antimicrobial therapy only (3), debridement and component retention (1) and two-staged exchange (2). All four patients treated without resection failed treatment a median of 2.5 months (range 2-11) after diagnosis and required resection arthroplasty. All six patients who underwent prosthesis removal (and exchange or arthrodesis) had successful outcome with a median duration of follow-up of 11 years (range 4-21). Three of these received oral antimicrobial therapy for a median duration eight weeks (range 4-8) and three received parenteral antimicrobial therapy for a median duration of six weeks (range 4-6).
\end{abstract}

Conclusions: The increase in Salmonella outbreaks does not seem to lead to increased Salmonella PJl. PJls due to Salmonella remain rare, and the presentation is often acute with fever. It frequently occurs in immunocompromised patients. In our patient population, removal of prosthesis with or without reimplantation, along with 4-6 weeks of effective parenteral antimicrobial therapy was most often associated with successful eradication of infection.

Keywords: Salmonella, Prosthetic joint infections, Arthroplasty

\section{Background}

By 2030, the annual number of combined knee and hip arthroplasties is estimated to reach four million in the United States [1]. Infections following joint prosthesis implantation occur at a frequency of $1-3 \%$, and are a major cause of morbidity and healthcare expenditure [2,3].

Staphylococci are the most common identified organism in prosthetic joint infections (PJIs). Salmonella are an enteroinvasive Gram- negative organism with capacity to cause bacteremia and seeding of various organs. Despite

\footnotetext{
* Correspondence: virka@mayo.edu

'Division of Infectious Diseases, Department of Medicine, Mayo Clinic, 200 1st Street SW, Rochester, MN 55905, USA

Full list of author information is available at the end of the article
}

their ability to cause native bone and joint infections, especially in immunocompromised individuals [4,5], Salmonella PJIs occur rarely. There have been numerous multi-state outbreaks of Salmonella gastroenteritis throughout the United States in the last decade despite regulatory measures [6-8]. Some of these outbreaks involve multi-drug resistant organisms [9]. Increased global travel has also predisposed individuals to acquire infection in areas of high Salmonella carriage rate.

While rates of Salmonella gastroenteritis have increased over the past decade, there have been only infrequent case reports of Salmonella PJIs in this time period [10-12]. Being a reportable disease, one can assume high levels 
of detection of Salmonella infection, especially PJI. The ideal management regimens and outcomes of these infections are also not well defined.

We therefore retrospectively reviewed all patients with a diagnosis of PJI caused by Salmonella seen at our institution between 1969-2013, and evaluated the demographics, management, and outcomes of these infections.

\section{Methods}

\section{Study design}

This is a single center retrospective case series undertaken at the Mayo Clinic, Rochester. The study was approved by our Institutional Review Board (IRB \# 14-001299, 03/07/ 2014). Medical and surgical therapies were not standardized and were performed at the discretion of the treating physicians.

\section{Study population and case ascertainment}

Study patients were evaluated at our institution between $1 / 1 / 1969$ and $12 / 31 / 2013$. Cases were ascertained by searching our institution's medical and surgical indices, and the microbiology database. Patients over 18 years of age that met our case definitions were included. Detailed information was abstracted from the medical records using a standardized data collection tool. Information was available for all patients. Patients were followed until the development of treatment failure, death or loss to follow- up. Descriptive statistics were used to summarize the demographic, clinical and treatment details and were analyzed using JMP, Version 9.0.1 (SAS Institute Inc.).

\section{Definitions}

Salmonella PJI was diagnosed if at least one of the following criteria was met: isolation of Salmonella species from two cultures of joint aspirates or intraoperative tissue specimens, purulence surrounding the prosthesis at the time of surgery with one positive joint culture yielding Salmonella species, acute inflammation consistent with infection on histopathological examination of periprosthetic tissue with one positive joint culture yielding Salmonella species, or sinus tract communicating with the prosthesis with one positive joint culture yielding Salmonella species.

Patients were either classified as having a good outcome or having failed treatment. Treatment failure was defined by one of the following criteria: recurrence of PJI due to the same Salmonella strain or a different microorganism; death due to prosthesis-related infection and indeterminate clinical failure, defined as clinical, laboratory, or radiological findings suggestive of PJI at any time after initial therapy. Patients who did not fulfill criteria for treatment failure were characterized as having a 'good outcome'.

Ethical Review Statement: IRB\# 14-001299 (03/07/2014) of the Mayo Clinic, Rochester.

\section{Results}

\section{Patient cohort}

In our cohort of six patients, median age at diagnosis of first episode of Salmonella PJI was 63.5 years (range 52-76). Five patients were male. Three patients were diagnosed prior to 1984 . A summary of the six patients is given in Table 1.

Five patients had a total hip arthroplasty (THA) infection while one patient had total knee arthroplasty (TKA) infection. Indication for joint arthroplasty included degenerative joint disease (3), and traumatic femoral head dislocation, rheumatoid arthritis and steroid induced avascular femoral head necrosis (1 each). Median age of prosthesis at time of diagnosis of first episode of Salmonella PII was five years (range 4 months-9 years). No patient had history of prior PJI on the same or different joint.

Five patients were immunosuppressed. One patient each had diabetes mellitus, chronic kidney disease, rheumatoid arthritis (RA), chronic lymphocytic leukemia (CLL) and ulcerative colitis taking 6-mercaptopurine (6-MP).

Five patients presented acutely with signs and symptoms present for less than two weeks. Median duration of symptoms prior to diagnosis was 4.5 days (range 2 days4 months). Only one patient, a 52 year-old-male with rheumatoid arthritis on steroids, presented with chronic symptoms (4 months of deep hip pain). All patients presented with local pain around the prosthesis. Four patients were febrile at presentation. None of the patients had an endovascular infection. None of the patients presented with or developed a discharge sinus during follow- up.

Two patients had diarrhea in the preceding two weeks before symptom onset, of which one had positive stool Salmonella culture, and two patients had documented Salmonella bacteremia before the PJI was diagnosed.

\section{Diagnosis}

All first episodes of Salmonella PJI were diagnosed in accordance with the definitions described in the methodology section. None of the first episodes had co-infection with another organism. Salmonella enterica serovar Enteritidis was the most common organism (4 patients) with $S$. enterica serovar Choleraesuis and $S$. bongori causing one infection each. All isolates were pan-susceptible with one being non-susceptible to nalidixic acid but susceptible to ciprofloxacin.

Median erythrocyte sedimentation rate (ESR) and $\mathrm{C}$ - reactive protein (CRP) values at presentation were $84 \mathrm{~mm} / 1^{\text {st }}$ hour (range 46-147), and $3.2 \mathrm{mg} / \mathrm{dL}$ (range 1.4- 8.3) respectively (normal range of ESR $0-22 \mathrm{~mm} / 1^{\text {st }}$ hour, and CRP $<8 \mathrm{mg} / \mathrm{dL}$ ). Three patients had available pathology reports; two had acute inflammation while one had fibroreactive changes without evidence of acute inflammation. 
Table 1 Summary of the 6 patients with 10 episodes of Salmonella Prosthetic joint infections ${ }^{1}$

\begin{tabular}{|c|c|c|c|c|c|c|c|c|c|}
\hline Patient no. & $\begin{array}{l}\text { Prosthetic } \\
\text { joint (indication) }\end{array}$ & Co-morbidities & $\begin{array}{l}\text { Prosthesis age at } \\
\text { time of infection }\end{array}$ & Clinical presentation & Microbiology & $\begin{array}{l}\text { Antimicrobial } \\
\text { therapy }\end{array}$ & $\begin{array}{l}\text { Surgical } \\
\text { management }\end{array}$ & $\begin{array}{l}\text { Failed } \\
\text { treatment }\end{array}$ & $\begin{array}{l}\text { Follow-up } \\
\text { duration }\end{array}$ \\
\hline \multirow[t]{2}{*}{1.} & Left TKA (RA) & $\begin{array}{l}\text { RA, Bladder } \\
\text { cancer }\end{array}$ & 3 years & $\begin{array}{l}\text { Deep joint pain, discomfort } \\
\times 4 \text { months }\end{array}$ & $\begin{array}{l}\text { Salmonella enterica } \\
\text { serovar Enteritidis } \\
\text { (aspirate) }\end{array}$ & $\begin{array}{l}\text { Oral TMP-SMX } \times 12 \\
\text { weeks }\end{array}$ & Aspiration only & Yes & 3 months \\
\hline & $"$ & $"$ & 3 years & $\begin{array}{l}\text { Pain in region of joint, unresolved } \\
\text { after } 3 \text { months of suppressive oral } \\
\text { therapy }\end{array}$ & " (operativesample) & $\begin{array}{l}\text { Oral TMP-SMX } \times 8 \\
\text { weeks }\end{array}$ & $\begin{array}{l}\text { Removal, debridement } \\
\text { and arthrodesis }\end{array}$ & No & 15 years \\
\hline \multirow[t]{2}{*}{2.} & Right THA (DJD) & $\begin{array}{l}\text { Colonic polyps } \\
\text { status post } \\
\text { colectomy }\end{array}$ & 6 years & $\begin{array}{l}\text { Cholecystectom y } 2 \text { weeks prior, } \\
\text { with positive blood and stool } \\
\text { cultures. Fever and joint pain } \times 5 \\
\text { days }\end{array}$ & $\begin{array}{l}\text { Salmonella enterica } \\
\text { serovar Enteritidis } \\
\text { (operative sample) }\end{array}$ & $\begin{array}{l}\text { IV ampicillin } x 4 \text { weeks } \\
\text { and oral amoxicillin } x \\
10 \text { months }\end{array}$ & Debride and retain & Yes & $\begin{array}{l}11 \\
\text { months }\end{array}$ \\
\hline & " & $"$ & 7 years & $\begin{array}{l}\text { Pain in region of prosthetic joint, } \\
\text { unresolved after } 11 \text { months of } \\
\text { suppressive oral therapy }\end{array}$ & " (operative sample) & IV ampicillin $\times 4$ weeks & $\begin{array}{l}\text { Removal, debridement } \\
\text { and arthrodesis }\end{array}$ & No & 8 years \\
\hline \multirow[t]{2}{*}{3} & $\begin{array}{l}\text { Left THA } \\
\text { (dislocated hip) }\end{array}$ & Diabetes mellitus & 5 months & $\begin{array}{l}\text { Fever, joint pain, joint swelling } \\
\text { starting } 5 \text { day prior, negative } \\
\text { stool cultures but diarrhea } \\
1 \text { week earlier }\end{array}$ & $\begin{array}{l}\text { Salmonella enterica } \\
\text { serovar Choleraesui s } \\
\text { (aspirate) }\end{array}$ & $\begin{array}{l}\text { Oral ampicillin } \times 8 \\
\text { weeks }\end{array}$ & Aspiration only & Yes & 2 months \\
\hline & " & " & 7 months & Continuing symptoms & " (operative sample) & $\begin{array}{l}\text { Oral ampicillin } \times 4 \\
\text { weeks }\end{array}$ & Two- stage exchange & No & 21 years \\
\hline 4. & Left THA (DJD) & $\begin{array}{l}\text { CLL, multiple skin } \\
\text { cancers }\end{array}$ & 4 years & $\begin{array}{l}\text { Fever, chills } \times 2 \text { days, Joint pain } \\
\text { and swelling } \times 2 \text { days }\end{array}$ & $\begin{array}{l}\text { Salmonella enterica } \\
\text { serovar Enteritidis } \\
\text { (operative sample) }\end{array}$ & $\begin{array}{l}\text { Oral ciprofloxacin } \times 8 \\
\text { weeks }\end{array}$ & Two- stage exchange & No & 10 years \\
\hline 5. & $\begin{array}{l}\text { Left THA } \\
\text { (aseptic necrosis) }\end{array}$ & $\begin{array}{l}\text { Ulcerative colitis, } \\
\text { now on 6-MP }\end{array}$ & 5 months & Fever and joint pain $\times 2$ weeks & $\begin{array}{l}\text { Salmonella enterica } \\
\text { serovar Enteritidis } \\
\text { (operative sample) }\end{array}$ & $\begin{array}{l}\text { IV ceftriaxone x } 6 \\
\text { weeks }\end{array}$ & Two- stage exchange & No & 12 years \\
\hline \multirow[t]{2}{*}{6.} & Left THA (DJD) & CKD, h/o stroke & 9 years & $\begin{array}{l}\text { Complicated Salmonella UTI and } \\
\text { septic shock } 1 \text { month prior, now } \\
\text { left hip joint pain } \times 4 \text { days }\end{array}$ & $\begin{array}{l}\text { Salmonella bongori } \\
\text { (aspirate) }\end{array}$ & $\begin{array}{l}\text { Oral ciprofloxacin } \times 8 \\
\text { weeks }\end{array}$ & Aspiration only & Yes & 2 months \\
\hline & $"$ & $"$ & 9 years & Continuing hip pain & $\begin{array}{l}\text { "+ MSCONS, viridans } \\
\text { group Streptococc us } \\
\text { sp., (operative sample) }\end{array}$ & $\begin{array}{l}\text { IV ceftriaxone } \times 6 \\
\text { weeks }\end{array}$ & Two- stage exchange & No & 4 years \\
\hline
\end{tabular}

${ }^{1} \mathrm{M}$ - male, F- female, TKA- total knee arthroplasty, THA- total hip arthroplasty, RA- rheumatoid arthritis, TMP-SMX - trimethoprim-sulfamethoxazole, DJD- degenerative joint disease, CLL- chronic lymphocytic leukemia, 6-MP- 6-mercaptopurine, CKD- chronic kidney disease, UTI- urinary tract infection, MSCONS- methicillin- susceptible Coagulase negative Staphylococci. 


\section{Management and outcome}

Four patients were initially managed without removal of prosthesis, of which three were diagnosed prior to 1984 and one patient diagnosed later initially declined surgical intervention. Three patients were initially managed with oral antimicrobial therapy alone (with diagnostic aspiration) for a median duration of 8 weeks (range 8-12), while one patient underwent debridement and retention of prosthesis along with four weeks of parenteral antimicrobial therapy and ten months of suppressive oral therapy. Three of these four patients were diagnosed prior to 1984 while one patient was diagnosed in 2010 (declined surgical intervention initially). The two patients, diagnosed in 1994 and 2002, that underwent a two-stage exchange as primary management were successfully treated.

Median time to treatment failure for the four patients managed non-operatively or with debridement and component retention was 2.5 months (range $2-11$ ). They all presented with incompletely resolved pain in the region of the prosthesis. Operative cultures identified the same organism as causing first PJI in all four patients, with one patient also growing methicillin- susceptible coagulasenegative Staphylococcus and viridans group Streptococcus species. Definite surgical therapy was later performed on all four patients, with two patients managed with implant removal and arthrodesis, and two with two- stage exchange.

In total, all six cases required removal of prosthesis for cure including four after failure of medical therapy alone. Median duration of follow- up after prosthesis removal was 11 years (range 4-21). Patients who underwent a two-stage exchange had a resection arthroplasty with placement of antibiotic (vancomycin and gentamicin) impregnated bone cement followed by delayed prosthesis re-implantation (6-8 weeks after prosthesis removal).

Three of the six patients managed with prosthesis removal received oral antimicrobial therapy (1 each trimethoprim-sulfamethoxazole, ampicillin and ciprofloxacin), median duration 8 weeks (range 4-8). Another three received parenteral antimicrobial therapy, median duration 6 weeks (range 4-6).

\section{Discussion}

Salmonella PJIs are rare and only 29 cases were identified in a recent literature review published in 2012 [13]. They were responsible for $0.2 \%$ of all PJIs at our institute over the study period. Salmonella illness remains a major public health problem in the United States, with an estimated 1.4 million human Salmonella infections, 15,000 hospitalizations, and 400 deaths annually [14]. There have been several multi-state outbreaks of Salmonella throughout the United States in the last decade despite regulatory measures, usually related to contaminated or inadequately processed food products and animal exposure [6-9]. This tremendous spike in Salmonella infections has not coincided with an increase in Salmonella PJI cases seen at a single center or reported in the literature. We did not see an increase in Salmonella PJI cases at our institute either. Perhaps these outbreak associated infections are less prone to causing PJI.

Salmonella are acquired through the feco-oral route or through animals or food. Almost half the patients with Salmonella PJI have gastroenteritis prior to diagnosis [15]. Two of six patients in our cohort had diarrhea prior to diagnosis of PJI with one having positive stool Salmonella culture. Initial gastrointestinal salmonellosis can be mild and may go unnoticed. The upsurge in food-borne illnesses in the United States [16] and recent reports highlighting PJIs caused by Campylobacter [17], Yersinia [18], and Clostridium difficile [19,20] suggest that patients and clinicians should be alert to diarrheal episodes in patients with prosthetic joints.

The route of Salmonella in causing PJI is generally considered to be hematogenous [21,22]. Salmonella can seed various organs, and their ability to cause native bone and joint infections is well recognized, especially in patients with sickle cell disease [22]. The time between implantation and infection can provide a clue about the source of infection with early and delayed PJI (joint age less than one year) more likely to be intra-operatively acquired. The literature shows varied time to infection with a range from 3 days - 14 years [13]. In our cohort, the median prosthesis age at infection was five years. Majority were THA, the significance of which is not clear. The detection of confirmed Salmonella bacteremia in two patients before the diagnosis of PJI (with the same species identified in operative cultures) supports hematogenous dissemination as the pathway for infection. Romero, et al. documented three episodes of Salmonella PJI in renal transplant recipients, two of which had a proven Salmonella urinary tract infection (UTI) prior to diagnosis [23], similar to one of our patients who had UTI and bacteremia a month prior to diagnosis of PJI.

The three patients in our cohort who did not have positive blood cultures or diarrhea prior to PJI were immunocompromised- one had CLL, other was taking steroids for RA, and the last one took 6-MP for ulcerative colitis. Chun, et al. have suggested that 'gut bacterial translocation' may be a portal of entry of Salmonella into the bloodstream, especially in immunodeficient individuals, as demonstrated in a patient with rheumatoid arthritis taking steroids who developed Salmonella PJI [24].

Non-typhoid Salmonella have traditionally caused PJIs more commonly than typhoidal Salmonella [13], with very few cases of the latter reported [25]. Salmonella enterica serovar Enteritidis was the most commonly isolated organism in our cohort. 
There have been reports of multi-drug resistant Salmonella strains causing bone and joint infections [22,26]. All the isolates in our cohort were pan-susceptible with a single isolate showing in-vitro resistance to nalidixic acid. Fluoroquinolones are widely advocated as excellent first choice drugs for Salmonella PJIs given their high oral bio-availability and ability to penetrate biofilms and kill stationary phase as well as active phase bacteria. Widmer, et al. demonstrated their efficacy over trimethoprimsulfamethoxazole (TMP-SMX) in curing Salmonella PJI and provided an explanation involving biofilms using a foreign body animal model [27]. Treatment failure has been reported with TMP-SMX use. [28] One patient in our cohort was treated with oral TMP-SMX initially. Although this patient failed treatment with oral TMP-SMX alone, infection was cleared with removal of the prosthesis and continuing oral TMP-SMX later.

PJI is primarily a surgical disease and most patients require surgical intervention for management. Although sporadic reports of successful management of Salmonella PJI have been reported with implant retention [12,29], other series have supported the use of prosthesis removal for successful outcome $[13,21,30]$. Based on current management consensus, patients with PJI symptoms less than 4 weeks can be treated with debridement and prosthesis retention. In patients presenting with discharge sinus or with symptoms greater than four weeks, two-stage exchange arthroplasty is indicated. Debridement alone had a high failure rate in our study despite acute onset of symptoms (median duration of symptoms was 4.5 days), and the same has been reported in patients with PJI caused by other Gram-negative organisms especially when the duration of symptoms is long [31]. In our cohort, all four patients who failed treatment were initially managed with implant retention and had successful outcomes with prosthesis removal. One patient in our cohort refused any surgical intervention initially (patient 4) and was hence given eight weeks of oral ciprofloxacin. When this did not result in resolution of symptoms, he allowed surgical intervention and was treated successfully using two-stage exchange and six weeks of parenteral ceftriaxone.

Reported success rates described in the literature may differ owing to the limited duration of follow-up, difference in the definition of a successful outcome, and the propensity for publication bias of successfully treated case reports. In our cohort, the median duration of follow up was eleven years. The major limitations to our study are inherent to its observational retrospective nature. The small sample size is a function of the low incidence of the disease. Since our data was collected from a single tertiary referral medical center, there is a potential for a referral bias. Management techniques have evolved over the long study period of more than forty years. Nevertheless, this series of
Salmonella PJIs supports the use of prosthesis removal in these patients.

\section{Conclusions}

The increase in Salmonella outbreaks does not seem to be leading to increased Salmonella PJI. Salmonella remains a rare but well recognized cause of PJI. Salmonella PJI should be suspected in patients with history of diarrheal illness, documented Salmonella infection elsewhere in the body, or in immunocompromised patients. Presentation is often acute with fever and local signs, and elevated ESR and CRP levels. Treatment requires a combined medical and surgical approach. Prosthesis removal is associated with higher chance of cure compared to implant retention. Both oral and parenteral antibiotics have been used for medical therapy guided by antimicrobial susceptibilities and patient characteristics.

\section{Competing interests}

The authors declare that they have no competing interests.

\section{Authors' contributions}

AG: collection, analysis and interpretation of the data, and writing of the article. EFB and DRO: critical revision of the manuscript for important intellectual content, and final approval. AV: conception and design, and final approval. All authors read and approved the final mansucript.

\section{Author details}

${ }^{1}$ Division of Infectious Diseases, Department of Medicine, Mayo Clinic, 200 1st Street SW, Rochester, MN 55905, USA. '2Department of Internal Medicine, UT Southwestern Medical Center, Dallas, Texas, USA.

Received: 10 July 2014 Accepted: 13 November 2014

Published online: 26 November 2014

\section{References}

1. Kurtz S, Ong K, Lau E, Mowat F, Halpern M: Projections of primary and revision hip and knee arthroplasty in the United States from 2005 to 2030. J Bone Joint Surg Am 2007, 89(4):780-785.

2. Zimmerli W, Trampuz A, Ochsner PE: Prosthetic-joint infections. N Engl J Med 2004, 351(16):1645-1654.

3. Sculco TP: The economic impact of infected joint arthroplasty. Orthopedics 1995, 18(9):871-873.

4. Le Dantec L, Maury F, Flipo RM, Laskri S, Cortet B, Duquesnoy B, Delcambre B: Peripheral pyogenic arthritis. A study of one hundred seventy-nine cases. Rev Rhum Engl Ed 1996, 63(2):103-110.

5. Goldenberg DL, Brandt KD, Cathcart ES, Cohen AS: Acute arthritis caused by Gram-negative bacilli: a clinical characterization. Medicine (Baltimore) 1974, 53(3):197-208.

6. Notes from the field: Multistate outbreak of Salmonella infantis, newport, and lille infections linked to live poultry from a single mail-order hatchery in Ohio-March-September, 2012. MMWR Morb Mortal Wkly Rep 2013, 62(11):213.

7. Notes from the field: Multistate outbreak of human Salmonella typhimurium infections linked to contact with pet hedgehogs - United States, 2011-2013. MMWR Morb Mortal Wkly Rep 2013, 62(4):73.

8. Notes from the field: multistate outbreak of Salmonella Altona and Johannesburg infections linked to chicks and ducklings from a mailorder hatchery - United States, February-October 2011. MMWR Morb Mortal Wkly Rep 2012, 61(11):195.

9. Outbreak of multidrug-resistant Salmonella typhimurium associated with rodents purchased at retail pet stores-United States, December 2003-October 2004. MMWR Morb Mortal Wkly Rep 2005, 54(17):429-433.

10. Toth K, Janositz G, Kovacs G, Sisak K, Rudner E: Successful treatment of late Salmonella infections in total hip replacement - report of two cases. BMC Infect Dis 2010, 10:160. 
11. Carlile GS, Elvy J, Toms AD: Salmonella infection of a total knee replacement. Knee 2010, 17(5):356-358.

12. Kobayashi H, Hall GS, Tuohy MJ, Knothe U, Procop GW, Bauer TW: Bilateral periprosthetic joint infection caused by Salmonella enterica serotype Enteritidis, and identification of Salmonella sp using molecular techniques. Int J Infect Dis 2009, 13(6):e463-e466.

13. De la Torre B, Tena D, Arias M, Romanillos O: Recurrent prosthetic joint infection due to Salmonella enteritidis: case report and literature review. Eur J Orthop Surg Traumatol 2012, 22(Suppl 1):S89-S97.

14. Voetsch AC, Van Gilder TJ, Angulo FJ, Farley MM, Shallow S, Marcus R, Cieslak PR, Deneen VC, Tauxe RV: FoodNet estimate of the burden of illness caused by nontyphoidal Salmonella infections in the United States. Clin Infect Dis 2004, 38(Suppl 3):S127-S134.

15. Musante DB, Ogden WS: Salmonella infection in joint arthroplasty. Orthopedics 2004, 27(7):770-772.

16. Incidence and trends of infection with pathogens transmitted commonly through food - foodborne diseases active surveillance network, 10 U.S. sites, 1996-2012. MMWR Morb Mortal Wkly Rep 2013, 62(15):283-287.

17. Vasoo S, Schwab JJ, Cunningham SA, Robinson TJ, Cass JR, Berbari EF, Walker RC, Osmon DR, Patel R: Campylobacter prosthetic joint infection. J Clin Microbiol 2014, 52:1771-1774.

18. Chol C, Blanc PL, Forel C: Yersinia enterocolitica infection of a prosthetic knee joint. Med Mal Infect 2008, 38(7):403-405.

19. Ranganath $\mathrm{S}$, Midturi JK: Unusual case of prosthetic shoulder joint infection due to Clostridium difficile. Am J Med Sci 2013, 346(5):422-423.

20. Curtis L, Lipp MJ: Clostridium difficile infection of a prosthetic knee joint requiring amputation. Surg Infect (Larchmt) 2013, 14(1):163-164.

21. Samra Y, Shaked Y, Maier MK: Nontyphoid salmonellosis in patients with total hip replacement: report of four cases and review of the literature. Rev Infect Dis 1986, 8(6):978-983.

22. Ortiz-Neu C, Marr JS, Cherubin CE, Neu HC: Bone and joint infections due to Salmonella. J Infect Dis 1978, 138(6):820-828.

23. Romero J, Schreiber A, Binswanger U: Late complications after total hip replacement in renal allograft recipients. Int Orthop 1994, 18(6):368-371.

24. Chen CY, Chen $\mathrm{CH}$, Lin KC, Hsu CJ, Renn JH: Recurrent prosthetic joint infection due to Salmonella enteritidis: case report and literature review. Eur J Orthop Surg Traumatol 2013, 23(2):239-240

25. Tattevin P, Cremieux AC, Joly-Guillou ML, Carbon C: First case of Salmonella hirschfeldii (paratyphi C) infection of a prosthetic hip. Clin Microbiol Infect 1998, 4(4):228-230

26. Sherman JW, Conte JE Jr: Ceftriaxone treatment of multidrug-resistant Salmonella osteomyelitis. Am J Med 1987, 83(1):137-138.

27. Widmer AF, Colombo VE, Gachter A, Thiel G, Zimmerli W: Salmonella infection in total hip replacement: tests to predict the outcome of antimicrobial therapy. Scand J Infect Dis 1990, 22(5):611-618.

28. Cheng N, Mulier JC: Salmonella osteomyelitis in total hip replacement. A case report of hematogenous infection from gastro-intestinal tract. Arch Orthop Trauma Surg 1982, 99(4):281-283.

29. Miron D, Zuker M, Lev-El A: Salmonella prosthetic knee septic arthritis successful retention of the prosthesis with prolonged suppressive therapy. Harefuah 2006, 145(4):261. -263, 319.

30. Day LJ, Qayyum QJ, Kauffman CA: Salmonella prosthetic joint septic arthritis. Clin Microbiol Infect 2002, 8(7):427-430.

31. Hsieh PH, Lee MS, Hsu KY, Chang YH, Shih HN, Ueng SW: Gram-negative prosthetic joint infections: risk factors and outcome of treatment. Clin Infect Dis 2009, 49(7):1036-1043.

doi:10.1186/s12879-014-0633-x

Cite this article as: Gupta et al.: Prosthetic joint infection due to Salmonella species: a case series. BMC Infectious Diseases 2014 14:633.

\section{Submit your next manuscript to BioMed Central and take full advantage of:}

- Convenient online submission

- Thorough peer review

- No space constraints or color figure charges

- Immediate publication on acceptance

- Inclusion in PubMed, CAS, Scopus and Google Scholar

- Research which is freely available for redistribution

Submit your manuscript at www.biomedcentral.com/submit

C Biomed Central 